\title{
The Application of FEM to Cathodic Corrosion Protection of Steel Reinforcement in Concrete
}

\author{
Masataka Masuda ${ }^{1}$, Makoto Arita ${ }^{1, *}$, Lee Eun $\mathrm{Ju}^{1}$, Kenshi Hanada ${ }^{1, *}$, \\ Hiroshi Minagawa ${ }^{2}$ and Koji Kawamata ${ }^{2}$ \\ ${ }^{1}$ Department of Materials Science \& Engineering, Faculty of Engineering, Kyushu University, Fukuoka 812-8581, Japan \\ ${ }^{2}$ Sumitomo Osaka Cement Co. Ltd., Tokyo 102-8465, Japan
}

Cathodic protection has been applied widely to steel reinforcement in concrete. However, it is generally very difficult to establish optimal corrosion protection for such steel and to precisely evaluate the corrosion protection effect. We evaluate the effects of various factors on the distribution of the protective current, and summarize the information for optimal corrosion protection. For this purpose we refined a numerical analysis technique using FEM to optimize the cathodic protection of the reinforcing steel in concrete. We have constructed a precise method to calculate the potential and current distribution in the concrete, which can account for ion migration, ion diffusion, and the polarization phenomena involving the anode and reinforcing steel. We have estimated the effect of anode shape on corrosion protection. The polarization properties derived from electrochemical measurements were used as boundary conditions for the FEM calculation. This calculation technique incorporates polarization behavior and variations of ion concentration due to ionic migration and diffusion, giving a precise estimate of the actual corrosion protection effect of a system. We have shown the typical effect of various factors on the current distribution for corrosion protection systems in concrete, as given by FEM.

(Received August 23, 2004; Accepted November 15, 2004)

Keywords: current distribution, laplace's equation, polarization, titanium anode, ion diffusion

\section{Introduction}

The early degradation of concrete structures poses a problem, and cathodic protection has recently gained in importance as one of the more useful corrosion protection methods, being quite effective and also easy to control and monitor. However, it is still difficult to evaluate the corrosion protection effect precisely, and to set up the proper anode arrangement and protection voltage. There are many factors involved that require analysis, such as the intricate form of steel reinforcement in concrete, alteration of the concrete's conductivity by changing ion concentrations and changing humidity. Also important are the electrochemical properties of the surface of the steel, which may be changed by the atmosphere, surface treatment, formation history, etc. Many numerical analyses for the corrosion protection design have been reported using a boundary element method (BEM) and obtained many valuable results. Cherry et al. measured and calculated the potential distribution of galvanic couples for the prediction of a corrosion phenomenon. ${ }^{1)}$ Bardal et al. evaluated the corrosion phenomenon controlled by the diffusion current. $^{2)}$ Brichau et al. analyzed numerically cathodic corrosion protection system for pipelines. ${ }^{3)}$ Miyasaka et al. have analyzed the cathodic corrosion protection system for sea-water pumps. ${ }^{4-7)}$ However, due to BEM calculation principles, they have treated the object area of calculation as a homogeneous electric conductor. The conductivity may become uneven in concrete and they can not be analyzed with conventional BEM method. In this study, corrosion protection is evaluated using a finite element method (FEM) that includes these numerous factors in the calculation, and a technique for monitoring the corrosion protection effect is also examined, in order to design optimal corrosion protection design for steel in concrete. In partic-

*Graduate Student, Kyushu University ular, a way to apply FEM calculations to this heterogeneous system, including ion diffusion in concrete and the local moisture content of the concrete, etc. is examined. We aimed to evaluate the effect of various factors on the protection current distribution, and to summarize the information for optimal corrosion protection of all concrete structures.

\section{Experimental}

\subsection{Theoretical approach}

The distribution of potential $\phi$ in the concrete complies with Laplace's equation: ${ }^{8)}$

$$
\nabla(\sigma \nabla \phi)=0
$$

where, $\sigma$ is the conductivity of concrete.

This inner potential value $\phi$ is not measurable, so the measurable electrode potential $E$ is used in its place. The relationship between $\phi$ and $E$ is shown as: ${ }^{9,10)}$

$$
E=\phi^{\mathrm{M}}-\phi^{\mathrm{R}}
$$

where $\phi^{\mathrm{M}}$ is the inner potential of a metal electrode, in this case, a steel or titanium anode, and $\phi^{\mathrm{R}}$ is that of a reference electrode.

Including the solution potential in eq. (2), we get:

$$
E=\phi^{\mathrm{M}}-\phi^{\mathrm{S}}+\phi^{\mathrm{S}}-\phi^{\mathrm{R}}
$$

This equation is rewritten and $\phi^{\mathrm{S}}$ is given by eq. (4):

$$
\phi^{\mathrm{S}}=-E+\phi^{\mathrm{M}}+\phi^{\mathrm{S}}-\phi^{\mathrm{R}}
$$

The value of $\left(\phi^{\mathrm{S}}-\phi^{\mathrm{R}}\right)$ is not measurable, but can be set to a constant, because this value consists of the potential difference between the electrode surface and a Luggin capillary tip, the solution potential difference of the salt bridge, and the boundary potential difference in the reference electrode. So the first value is eliminated by suitable positioning of the Luggin capillary, and the second and third values are set 
constant by stable measuring conditions for the solution composition, temperature etc., making the value of $\left(\phi^{\mathrm{S}}-\phi^{\mathrm{R}}\right)$ treatable as a constant value that can be expressed as a $\Delta \phi$. Using $\Delta \phi$, eq. (4) becomes:

$$
\phi^{\mathrm{S}}=-E+\phi^{\mathrm{M}}+\Delta \phi
$$

This potential value is not measurable, but a new value $u$, obtained by subtracting $\left(\phi^{\mathrm{M}}+\Delta \phi\right)$ from $\phi^{\mathrm{S}}$, is measurable $(-E)$ and satisfies Laplace's eq. (1). Using $\phi^{\mathrm{M}}$ for steel, the new potential value is defined as follows:

$$
\begin{aligned}
u & \equiv \phi^{\mathrm{S}}-\left(\phi_{\text {steel } \left.^{\mathrm{M}}+\Delta \phi\right)}\right. \\
& =-E+\left(\phi^{\mathrm{M}}+\phi_{\text {steel }}^{\mathrm{M}}\right)
\end{aligned}
$$

So the potentials of steel and the titanium anode electrode potential are defined as:

$$
\begin{aligned}
& u_{\text {steel }}=-E_{\text {steel }}
\end{aligned}
$$

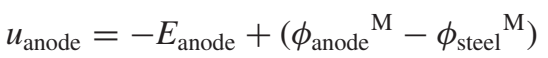

where, $\phi_{\text {steel }}^{\mathrm{M}}$ and $\phi_{\text {anode }}{ }^{\mathrm{M}}$ are the inner potential of steel and anode, and $E_{\text {steel }}$ and $E_{\text {anode }}$ are the electrode potential of steel and anode. These equations mean that the potential for FEM calculation is defined by a measurable value. Also, $\left(\phi_{\text {anode }}{ }^{\mathrm{M}}-\phi_{\text {steel }}{ }^{\mathrm{M}}\right)$ is equal to the external supplied potential, so using this value as $V_{\text {protect }}$, eq. (7) becomes:

$$
u_{\text {anode }}=-E_{\text {anode }}+V_{\text {protect }}
$$

There are two boundary conditions: at the insulation wall and at the metal electrode surface. At the insulation wall, the current doesn't flow through the wall, so its boundary condition can be written as follows:

$$
n \cdot(\sigma \nabla u)=0
$$

where $n$ is a vector normal to the insulation wall.

On the surface of both steel and anode, there is a polarization phenomenon that accompanies the current flows. The polarization behavior is described with an equilibrium potential $E^{0}$ and an overpotential as a function of current, as follows:

$$
\begin{aligned}
& E_{\text {steel }}=E_{\text {steel }}{ }^{0}-\eta_{\text {steel }}(j) \\
& E_{\text {anode }}=E_{\text {anode }}{ }^{0}+\eta_{\text {anode }}(j)
\end{aligned}
$$

Using these equations, boundary conditions (6) and (8) are rewritten as follows:

$$
\begin{aligned}
& u_{\text {steel }}=E_{\text {steel }}{ }^{0}+\eta_{\text {steel }}(j) \\
& u_{\text {anode }}=-E_{\text {anode }}{ }^{0}-\eta_{\text {anode }}(j)+V_{\text {protect }}
\end{aligned}
$$

Measurement of the polarization curves gives $E^{0}$ and $\eta(j)$, so all boundary conditions have been defined and FEM calculations can proceed.

Next we consider the time dependent terms, diffusion, migration and convection of ions.

Factors that affect the conductivity of the electrolyte are ion concentrations, electric field and the flow of electrolyte, but the flow of electrolyte in concrete is negligible. Accordingly, a governing equation is expressed below with respect to the concentration $c_{i}$ of ion $i$;

$$
\frac{\partial c_{i}}{\partial t}=-\nabla\left(D_{i} \nabla c_{i}\right)-z_{i} u_{i} F c_{i} \nabla \phi
$$

where, $t$ is time, $D_{i}$ is the diffusivity of ion $i, z_{i}$ is the charge on the ion $i, u_{i}$ is the mobility of ion $i, F$ is Faraday's constant and $\phi$ is potential.

This formula is similar for all the target ions, and is solved under the condition of electrical neutrality.

Relating these two eqs. (1) and (14), the potential and current distribution is solved as a function of concentration and time. First, we find potential distribution with eq. (1). Next, solving eq. (14) by using this potential value and a certain time step, we obtain the conductivity distribution, as mentioned later. Then, using this result from eq. (1), we obtain a new potential distribution. This loop is iterated for a set time to yield the solution.

A tetrahedron is used as the element for 3-dimensional FEM calculations, and a triangle for 2-dimensional structures.

In Figs. 3, 4, 5, 6, 10 and 12 (2 dimensional models), the number of elements is 16,000 , with 250 boundary elements and a minimum element quality of approximately 0.6.

In Figs. 7, 8 and 11 (3-dimensional model), the number of elements is 300000, with 12000 boundary elements, 700 edge elements and a minimum element quality of approximately 0.2 .

Galerkin's method was used to solve the matrix.

The non-linear problem was solved with the following conditions;

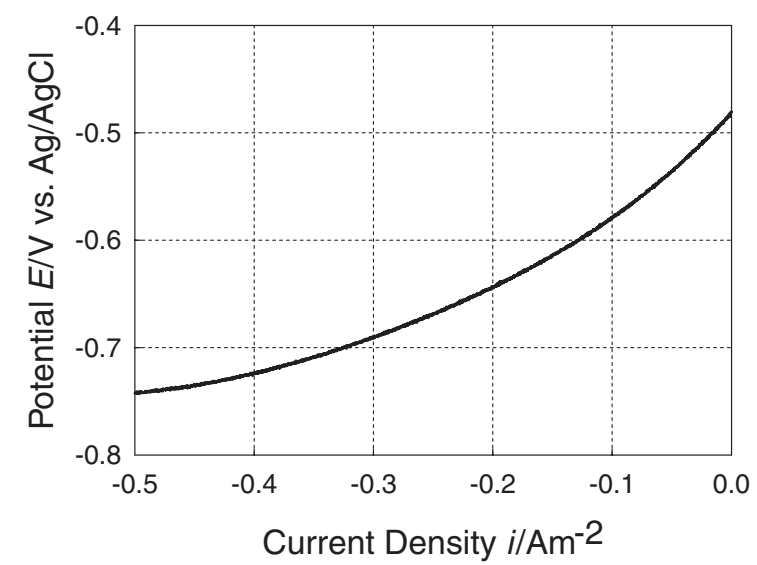

Fig. 1 Polarization curve of reinforcing steel in saturated $\mathrm{Ca}(\mathrm{OH})_{2}$ solution.

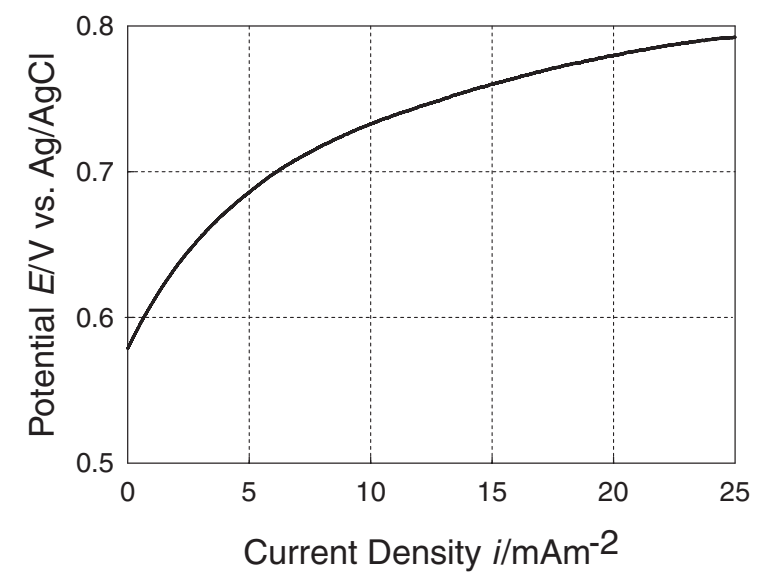

Fig. 2 Polarization curve of titanium anode in saturated $\mathrm{Ca}(\mathrm{OH})_{2}$ solution. 


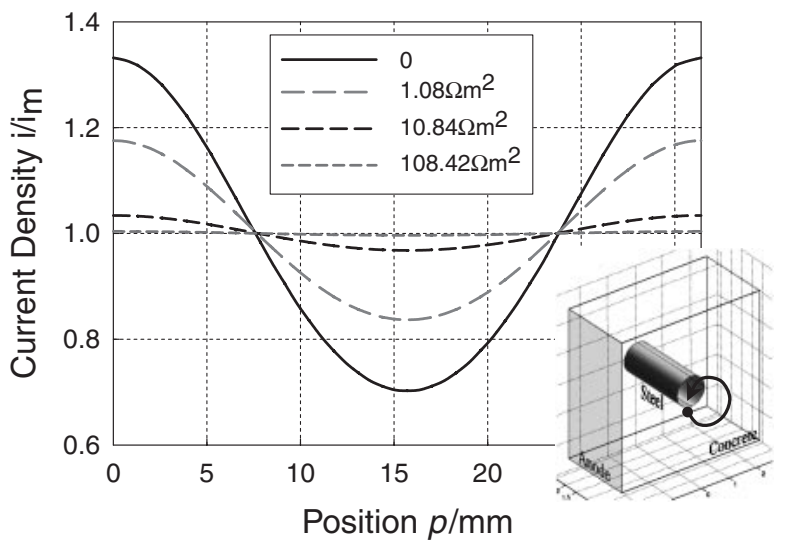

Fig. 3 Current distribution on the reinforcing steel with polarization resistance.

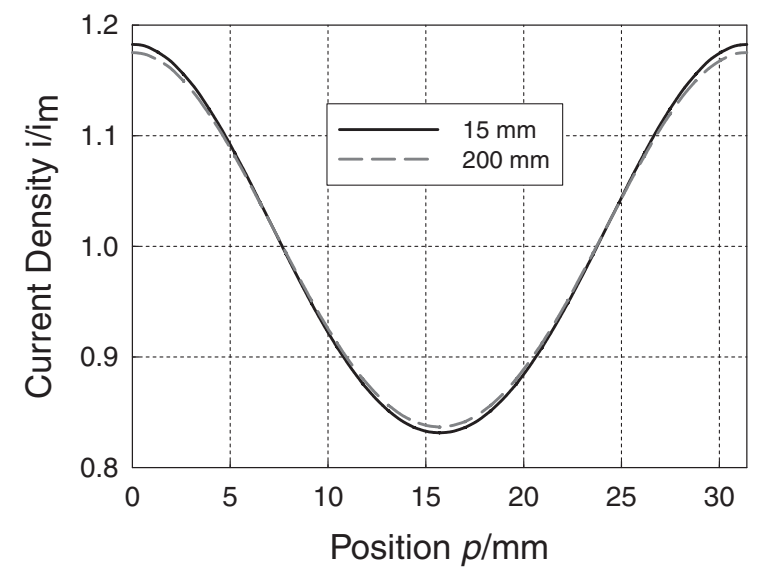

Fig. 4 Effect of coverage depth of steel on current distribution.

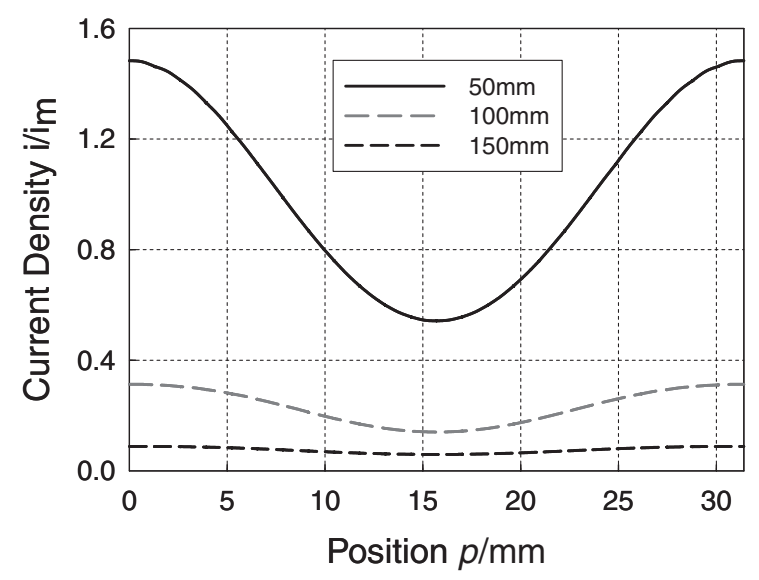

Fig. 5 Current distributions of multilayered steels.

A) The relative tolerance is $1.0 \times 10^{-6}$.

B) The maximum tolerance number is 100 .

C) Constraint handling is by the elimination method, and null-space handling is by orthonormal function.

D) The assembly block size is 5000 .

The time-dependent model of Fig. 10 was solved from $0 \mathrm{~s}$ to $152 \mathrm{Ms}$ with time step of $10 \mathrm{ks}$, with the following conditions:

A) The relative tolerance is 0.01 .

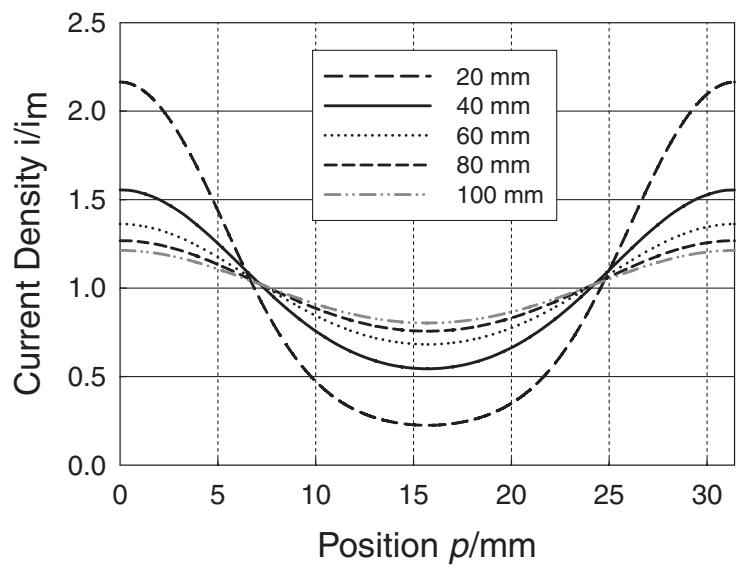

Fig. 6 Influence of distance between neighboring steel on current distribution.

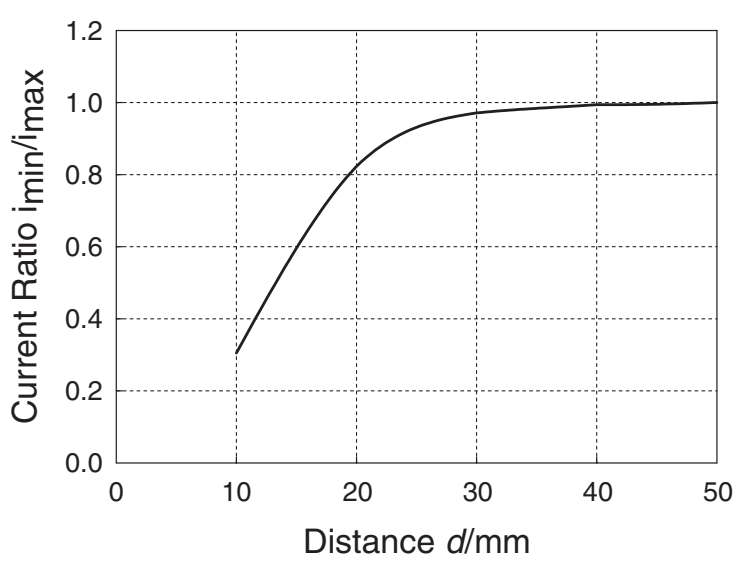

Fig. 7 Effect of distance between anode and cathode on cathodic current ratio.

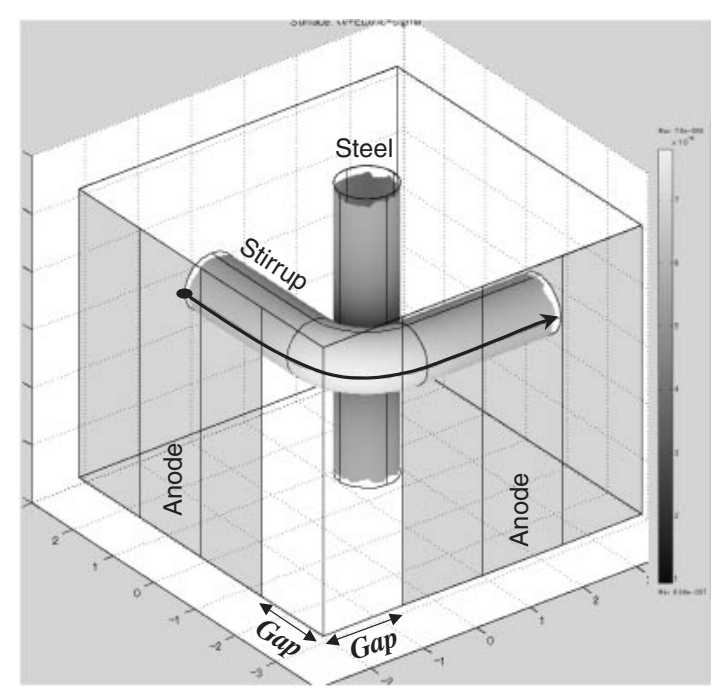

Fig. 8 Stirrup and steel in concrete of a quarter section of pillar.

B) The consistent initialization of DAE systems is backward Euler method.

C) The error estimation strategy is the inclusive algebraic method. 


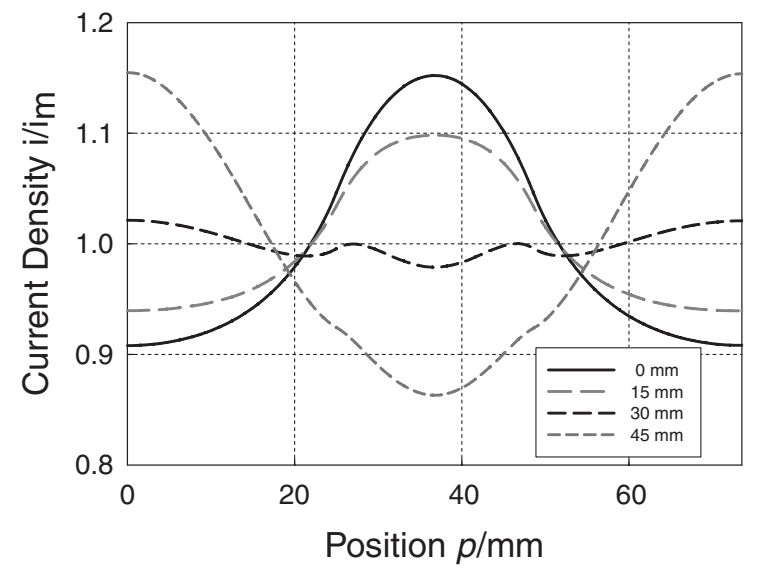

Fig. 9 Current distribution on stirrup with anode gap.

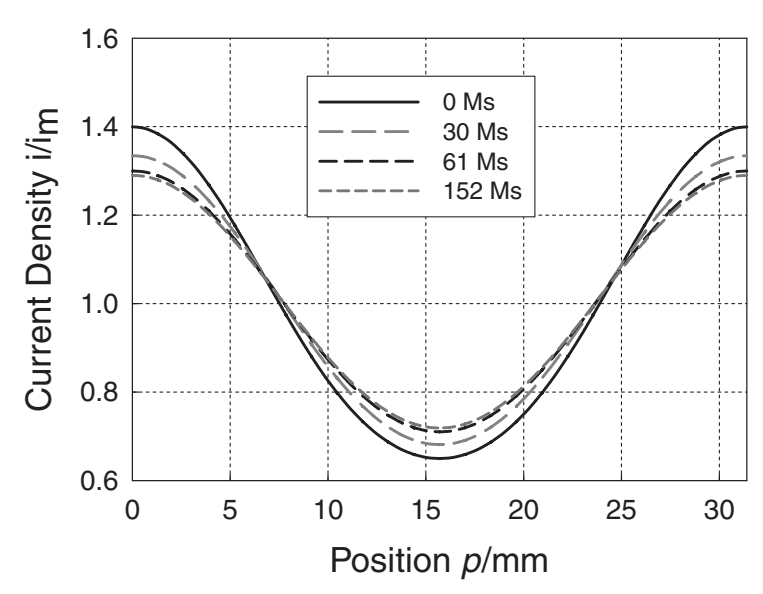

Fig. 10 Current distribution with $\mathrm{NaCl}$ diffusion time

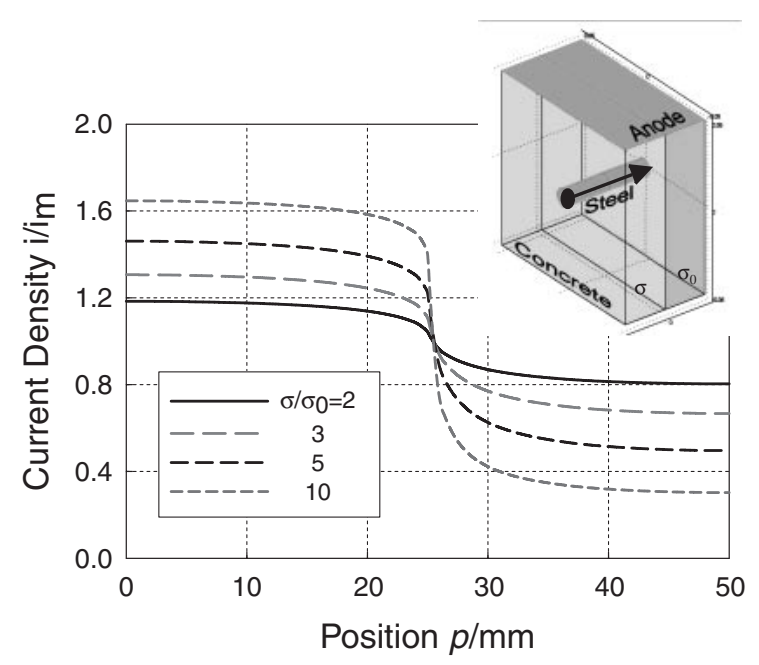

Fig. 11 Variation of cathodic current distribution with conductivity deviation.

The boundary conditions were set as the following:

On the insulation wall and symmetric boundary, Neumann boundary

$$
\mathrm{d} \phi / \mathrm{d} n=0
$$

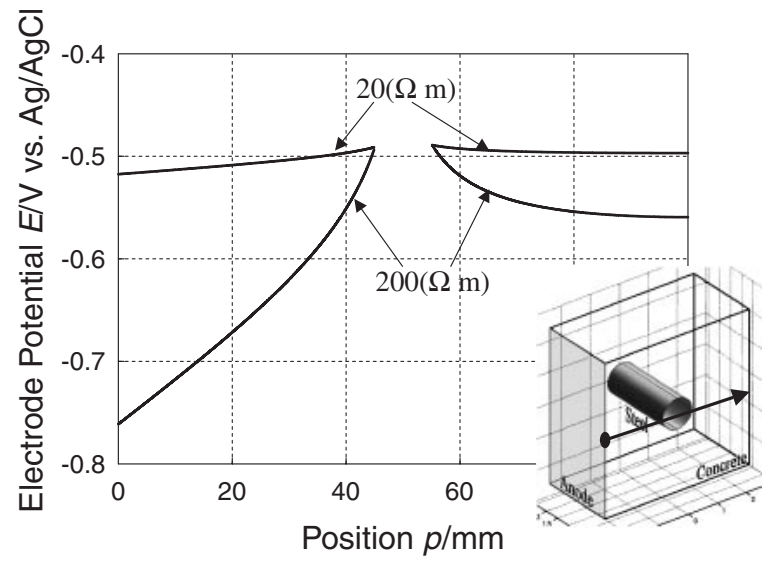

Fig. 12 Effect of monitor position on measured cathodic potential.

was used, where $n$ is normal vector to the boundary.

On the steel rod and the anode, Robin boundary, the current was approximated with a linear function of the potential using the polarization curves, and the relationship between the current $i$ and potential $E$ was given by:

$$
i=\left(E-E_{0}\right) / r_{\mathrm{p}}
$$

where $E_{0}$ is the equilibrium potential and $r_{\mathrm{p}}$ is polarization resistance.

Furthermore, using model reinforced concrete structures, we confirmed good agreement between measured and calculated values using the present method. ${ }^{11)}$

\subsection{Polarization measurements}

The polarization measurements for reinforcing steel (JIS SBPD 130/145) rod and titanium anode plate were made with a potentiostat (HOKUTO DENKO, HA301) in saturated calcium hydroxide solution in ambient air. The potential scanning rate was $1 \mathrm{mV} / \mathrm{s}$ with a reference electrode of saturated $\mathrm{KCl}-\mathrm{Ag} / \mathrm{AgCl}$. This measurement gave the relationship between the electrode potential and the current, which was used as a boundary condition on the surface of the steel and titanium anodes.

\section{Results and Discussion}

\subsection{Polarization curve}

The polarization curves of reinforcing steel and a titanium anode are shown in Figs. 1 and 2. The polarization behavior is affected by the steel type (composition, formation history and surface treatment) and the concrete type (composition, ion concentration, humidity). In this study, we measured the polarization curves of the typical reinforcing steel and a titanium anode in an imitation concrete solution, and evaluated the effects of electrochemical properties on cathodic protection. Taking the tangent at a current density of $20\left(\mathrm{~mA} / \mathrm{m}^{2}\right)$, we set $-0.483 \mathrm{~V}$ (vs. $\mathrm{Ag} / \mathrm{AgCl}$ ) as the equilibrium electrode potential, and $1.084 \Omega \mathrm{m}^{2}$ as the polarization resistance for steel, $+0.707 \mathrm{~V}$ (vs. $\mathrm{Ag} / \mathrm{AgCl}$ ) and $3.550 \Omega \mathrm{m}^{2}$ for the titanium anode. Using this polarization curve, the relationship between electrode potential and current was obtained and was used as the boundary condition for the FEM. 


\subsection{Effect of polarization on cathodic current distribu- tion on the steel surface}

The calculated current density distribution of cathodic protection on the reinforcing steel is shown in Fig. 3. Here, a $10 \mathrm{~mm}$ diameter steel rod was centered in a $100 \times 100 \mathrm{~mm}^{2}$ block of concrete, and a titanium anode covered one surface of the concrete. The horizontal axis shows the position on the circumference of the steel, with the nearest point to the anode being $0 \mathrm{~mm}$, the opposite point $15.7 \mathrm{~mm}$, and the once-around point $31.4 \mathrm{~mm}$, as indicated by the arrow of the inset figure. The current density is normalized by the mean current density.

In a saturated $\mathrm{Ca}(\mathrm{OH})_{2}$ solution, the polarization resistance of steel is $1.084 \Omega \mathrm{m}^{2}$, but in real concrete, this will vary with the concrete composition, atmosphere, steel type, and surface treatment of the steel. Figure 3 shows the polarization resistance effect on current distribution. The current distribution deviates remarkably from uniformity in the case of the non-polarization surface, and clearly becomes uniform with increasing polarization resistance. However, the change in equilibrium electrode potential had very little effect on current distribution under a constant protection current condition.

The electrical resistance for protection current consists of the electrochemical reaction resistance at the electrode surface and the conduction resistance in the concrete. The latter depends on the geometrical shape of the concrete construction. These resistances are connected in series, so an increment in reaction resistance decreases the effect of conduction resistance and the effect of geometrical form, and the current distribution becomes more uniform. For example, when steel has mill scale on its surface, the polarization resistance will increase and the cathodic protection current distribution will become uniform.

\subsection{Effect of cover depth on cathodic current distribu- tion}

The effect of the coverage depth of steel on the current distribution is shown in Fig. 4. In this case, the diameter of the steel is $10 \mathrm{~mm}$, the distance between rods is $50 \mathrm{~mm}$ and depth of concrete is $500 \mathrm{~mm}$. This figure shows that a coverage depth of more than $15 \mathrm{~mm}$ does not further alter the current distribution. Under the guidelines for concrete construction, ${ }^{12-15)}$ the suitable coverage depth is greater than the steel diameter, and $25 \mathrm{~mm}$ for slab, $30 \mathrm{~mm}$ for girder and $35 \mathrm{~mm}$ for pillar, respectively. We confirmed that the coverage depth does not affect the current distribution as long as this guideline is observed.

Current distributions for multilayered reinforcing steels are shown in Fig. 5. Three samples of $10 \mathrm{~mm}$ diameter are buried at a depth of $50 \mathrm{~mm}, 100 \mathrm{~mm}$ and $150 \mathrm{~mm}$ from the surface of the concrete. The current ratios for these steels are calculated as 1.00:0.23:0.075 in order of depth. The current density at the steel surface decreases with increasing depth from the concrete surface, but the current distribution for $50 \mathrm{~mm}$ deep steel is more disordered than that of Fig. 4. Figures 4 and 5 suggest that the cathodic current of areas far from the anode branched to other embedded pieces. In the case of multi-layered steel, it should be noted that the current distribution shows greater disorder than for simple steel.

\subsection{Effect of the inter-rod distance on current distribu- tion}

The influence of the distance between neighboring reinforcing steel rods on the current distribution is shown in Fig. 6. In this case, the reinforcing steel diameter and cover depth are $10 \mathrm{~mm}$ and $25 \mathrm{~mm}$, respectively. It was shown that the protection current distribution becomes disordered with decreasing rod distance. The guideline recommends more than $40 \mathrm{~mm}$ and 1.5 times the rod diameter as the distance between steel rods in a pillar, and over $20 \mathrm{~mm}$ and 1.0 times in a girder. The calculation showed that these minimum distances are not suitable for cathodic protection. We recommend 4 or more diameters between steel rods for cathodic protection.

\subsection{Effect of the anode mesh shape on current distribu- tion}

For cathodic protection, a titanium alloy mesh coated with a noble metal is used as the anode for current supply because of its chemical stability and small overpotential. We evaluated the effect of this anode shape on cathodic protection current distribution. A titanium anode with an $82 \mathrm{~mm} \times 37 \mathrm{~mm}$ diamond-shaped mesh of $1 \mathrm{~mm}$ diameter wire was evaluated as the typical anode sample. Using an opposite flat plane cathode as the corrosion protection target, the current distribution on the cathode plate was calculated as a function of the distance between the anode and the cathode. The results are shown in Fig. 7. Here, the current ratio $i_{\min } / i_{\max }$ means the ratio of the minimum current density to the maximum current density on the cathode surface. This figure shows that the anode mesh shape doesn't affect the current distribution on the cathode surface at distances beyond $40 \mathrm{~mm}$. This result was also found for other anode mesh shapes, and we confirmed that the anode mesh shape didn't affect the current distribution on the cathode at the distances larger than the hole diameter of the anode mesh. This result says that the suitable cover depth for cathodic protection is larger than the smallest hole diameter of an anode mesh.

\subsection{Effect of anode width on the cathodic current distribution}

For the construction of a cathodic protection system, it is very important to estimate the minimum required area of anode for economy of function and construction. It improves the cathodic protection system to estimate the optimal anode shape. We evaluated the effect of anode width on the cathodic current distribution of a cathode. The calculation object is stirrup and rods whose quarter section is shown in Fig. 8. A stirrup and four rods of $10 \mathrm{~mm}$ diameter steel are set in a $120 \mathrm{~mm} \times 120 \mathrm{~mm}$ section of concrete. For symmetry reasons, only a quarter section was calculated, and Fig. 8 indicates the current distribution on the steel surface by brightness. A bright area means higher current density, and a dark area means lower density. Figure 9 shows the cathodic current distribution on the stirrup steel. The horizontal axis shows the position on the stirrup surface, with $0 \mathrm{~mm}$ the center of the pillar face, $36.5 \mathrm{~mm}$ a corner, and $73 \mathrm{~mm}$ a center of another pillar face, as indicated by the arrow in Fig. 8. The different curves in Fig. 9 shows the distance of 
the anode form the edge of the concrete, showing how current density at a corner increases with the decreasing distance. The calculation showed that the current density at the corner of a stirrup rose to over $115 \%$ of the mean value as the anode covered the entire concrete surface, and that an anode and a cathode should have the same length for optimal cathodic protection.

\subsection{Effect of ion diffusion on the current distribution}

The corrosion current distribution is affected by the sprinkling of snow-melting agents and the splash of seawater on a concrete surface, as the concentrated deposits of ions diffuse from the concrete surface inwards. ${ }^{16)}$ We calculated the change of the cathodic protection current distribution where seawater adhered to the surface and diffused to the inside of the concrete. Diffusivities of typical ions in the concrete were calculated with equivalent ionic conductivities in aqueous solution. ${ }^{17)}$ Table 1 shows the ionic species and their properties as used for the calculation.

The initial ion concentration profiles are shown in Table 2. We assumed that the concentration profile at the concrete faced in contact with seawater was constant.

We assumed that the conductivity of concrete was determined by the 3 kinds of bases and salt in Table 3 . Using the relationship between conductivity and concentration in aqueous solution, the conductivity was approximated with a quadratic function of the concentration to determine the conductivity of concrete. ${ }^{10)}$

Using these values, the FEM calculation was performed for a model with a steel rod $10 \mathrm{~mm}$ in diameter in the center of a $100 \times 100 \mathrm{~mm}^{2}$ piece of concrete with a titanium anode on one surface, and ions diffusing from the anode surface. It was shown that the concentration of $\mathrm{Na}^{+}$and $\mathrm{Cl}^{-}$near the reinforcing steel rod was slightly higher than in the

Table 1 Ionic species and properties.

\begin{tabular}{lcc}
\hline ion & $\begin{array}{c}\text { Diffusivity } \\
D / 10^{-9} \mathrm{~m}^{2}\end{array}$ & $\begin{array}{c}\text { Mobility } \\
u / 10^{-8} \mathrm{~m}^{2} \mathrm{~V}^{-1} \mathrm{~s}^{-1}\end{array}$ \\
\hline $\mathrm{Ca}^{2+}$ & 0.792 & 6.167 \\
$\mathrm{Na}^{+}$ & 1.334 & 5.194 \\
$\mathrm{~K}^{+}$ & 1.957 & 7.620 \\
$\mathrm{Mg}^{2+}$ & 0.706 & 5.499 \\
$\mathrm{Cl}^{-}$ & 2.032 & 7.912 \\
$\mathrm{OH}^{-}$ & 5.260 & 20.480 \\
$\mathrm{SO}_{4}{ }^{2-}$ & 1.065 & 8.291 \\
\hline
\end{tabular}

Table 2 Initial ion concentration profiles.

\begin{tabular}{lcc}
\hline \multirow{2}{*}{ ion } & \multicolumn{2}{c}{ concentration $c / 10^{-3} \mathrm{~mol} \cdot \mathrm{m}^{-3}$} \\
\cline { 2 - 3 } & Surface & Concrete \\
\hline $\mathrm{Ca}^{2+}$ & 20.0 & 7.2 \\
$\mathrm{Na}^{+}$ & 459.2 & 65.2 \\
$\mathrm{~K}^{+}$ & 9.7 & 47.0 \\
$\mathrm{Mg}^{2+}$ & 104.7 & 4.5 \\
$\mathrm{Cl}^{-}$ & 535.4 & 0.2 \\
$\mathrm{OH}^{-}$ & 0.0 & 117.9 \\
$\mathrm{SO}_{4}{ }^{2-}$ & 55.2 & 5.8 \\
\hline
\end{tabular}

Table 3 Conduction as a function of concentration. $c$ : concentration/ $\mathrm{mol} \mathrm{m}^{-3}$.

\begin{tabular}{cc}
\hline Compound & Conductivity $\sigma / \mathrm{S} \cdot \mathrm{m}^{-1}$ \\
\hline $\mathrm{Ca}(\mathrm{OH})_{2}$ & $-1.026 \times 10^{-1} c^{2}+23.05 c$ \\
\hline $\mathrm{NaOH}$ & $-3.627 \times 10^{-3} c^{2}+19.46 c$ \\
\hline $\mathrm{KOH}$ & $-2.696 \times 10^{-3} c^{2}+23.57 c$ \\
\hline $\mathrm{NaCl}$ & $-8.781 \times 10^{-4} c^{2}+0.9335 c$ \\
\hline
\end{tabular}

surroundings, because the diffusion of ions was obstructed by the steel rod. The ionic concentration gradient altered the conductivity of the concrete, which changed the current distribution as shown in Fig. 10. The current distribution around the steel becomes uniform with the progress of ionic diffusion, as the conductivity inside the concrete increases. When the ions diffused from the concrete surface into the interior, corrosiveness increased in the high-ion region. And because the conductivity increased simultaneously, the cathodic protection current flowed easily in this region. It is clear that cathodic protection affords an excellent defense against corrosion caused by ionic diffusion.

In this calculation, we only took into account the diffusion and migration of ions and conductivity deviations. However, in a strict sense, ionic concentration deviations directly affect the corrosion behavior of steel, so we must also consider the change in corrosion resistance caused by ionic diffusion. This calculation is in progress, and results will be reported in a subsequent paper.

\subsection{Effect of concrete conductivity on current distribu- tion}

If moisture penetrates into concrete, the conductivity of the concrete will change locally and then the cathodic current will change. As a calculation model, we used a $100 \mathrm{~mm} \times$ $100 \mathrm{~mm}$ section of concrete with a $10 \mathrm{~mm}$ reinforcing rod in the center. Figure 11 shows the variation of cathodic current distribution on the steel surface with humidity. The left half of the curve is the steel in a concrete of a high conductivity and the right half is the steel in a concrete of a low conductivity. In this figure, $\sigma$ means a higher conductivity and $\sigma_{0}$ means a lower one. While the conductivity of the left half increases to double or even 10 times of that of the right half, the cathodic current flow is greater to the left half by 1.5-5.5 times. It was shown that the cathodic current distribution changed drastically when the conductivity changed locally as in this example, although the cathodic current changed little when the humidity diffused into the concrete homogeneously and the conductivity of the concrete increased homogeneously. Generally, when the conductivity of concrete increases, the corrosiveness increases. Accordingly, the cathodic protection method is very effective as corrosion protection because the protection current can preferentially self-direct to the more corrosive areas.

\subsection{Effect of monitoring electrode position on measure- ment of corrosion potential}

Precise monitoring of the corrosion potential of the reinforcing steel is required for appropriate evaluation of corrosion protection. We evaluated the effect of the position 
of a monitoring electrode in concrete on the accuracy of the measured corrosion potential. The change of the measured cathodic potential of the reinforcing steel with the position of the monitoring electrode is shown in Fig. 12. As a calculation model, we used a $100 \mathrm{~mm} \times 100 \mathrm{~mm}$ section of concrete with a $10 \mathrm{~mm}$ reinforcing rod in the center. Figure 12 shows the electrode potential against an $\mathrm{Ag} / \mathrm{AgCl}$ reference electrode. The cathodic protection current density was $20 \mathrm{~mA} / \mathrm{m}^{2}$ on the concrete surface, and the resistivity of the concrete was set $20 \Omega \mathrm{m}$ and $200 \Omega \mathrm{m}$. The monitor electrode was set on the concrete surface perpendicularly over the reinforcing steel, and the horizontal axis in Fig. 12 shows the distance from the concrete surface, as shown with the arrow in the inset figure. The interval from $45 \mathrm{~mm}$ and $55 \mathrm{~mm}$ is the reinforcing steel and the anode is at $0 \mathrm{~mm}$. This figure shows that measured cathodic potential decreases with increasing distance between monitor and steel. The amount of change is affected by the resistivity of the concrete and the measured potential becomes lower with the resistivity increment. In $20 \Omega \mathrm{m}$ concrete, the monitoring electrode should be set within $10 \mathrm{~mm}$ of the reinforcing steel, to avoid a measuring error exceeding $10 \mathrm{mV}$. This result is very important for monitoring the real electrode potential of reinforcing steel, and will be help optimize monitoring of corrosion protection. Also, this calculation can provide information about the optimal position for monitoring electrodes. We will expand on this in our next paper.

\section{Conclusion}

We refined a FEM to evaluate the current distribution involved in cathodic corrosion protection of reinforcing steel in concrete of uneven conductivity and discussed the effects of some key factors on the current distribution.

1) The polarization resistance of steel

The cathodic protection current distribution of cylindrical steel rod becomes uniform when the polarization resistance of the steel increases.

2) The position of steel in concrete

The cover depth has very little effect on the cathodic current distribution. However, for multiple layers of steel, deviations of the current distribution on the top layer are larger because of the current flows to the inside layers.

When the spacing between the steels is less than 2 times the cover depth, the current distribution on the surface becomes uneven.

3) Anode mesh shape
The shape of the anode mesh hole does not affect the current distribution on the steel, if the cover depth is larger than the mesh hole diameter.

4) Current distribution at the edges of steel rods

It is suitable for obtaining a uniform cathodic protection current at the edges of steel that the covering length of the anode is the same as the steel's length.

5) Ion diffusion in concrete

When ions diffuse from the concrete surface, the current distribution becomes uniform because the conductivity of the concrete increases.

6) Position of monitoring electrode

For high accuracy measurement of protection potential, it is recommended that the monitoring electrode is set within $10 \mathrm{~mm}$ of reinforcing steel.

We hope that this information will help optimize cathodic corrosion protection.

\section{REFERENCES}

1) B. W. Cherry, M. Foo and T. H. Siauw: Corrosion 42 (1986) 654-662.

2) E. Bardal, R. Johnsen and P. O. Gartland: Corrosion 40 (1984) 628633.

3) F. Brichau, J. Deconinck and T. Driesens: Corrosion 52 (1996) 480488.

4) M. Miyasaka, H. Rakayama and K. Amaya: Zairyo-to-Kankyo, 146 (1997) 378-383.

5) M. Miyasaka, J. Ishiguro and K. Kishimoto: Zairyo-to-Kankyo, 44 (1995) 226-232.

6) M. Miyasaka, K. Amaya and S. Aoki: Zairyo-to-Kankyo 44 (1995) 293-299.

7) M. Miyasaka, H. Takayama, K. Amaya and S. Aoki: Zairyo-toKankyo, 47 (1998) 156-163.

8) J. Newman: Electrochemical systems, (Prentice-Hall, 1973) pp. 386399.

9) R. Tamamushi: Electrochemistry, (Tokyo Kagaku Doujin, 1975) pp. 228-252.

10) C. Wagner: J. Electrochem. Soc. 98 (1951) 116-128.

11) Repair construction method research committee report of the concrete structure, Japan Soc. of Concrete Eng., Oct. (1994) pp. 204-215.

12) Standard Guideline Book of Concrete Construction, (Japan Soc. of Civil Eng., 1996) pp. 106.

13) Y. Miyazaki: Pre-stressed Concrete Manual, (Kougaku Shuppan, 1983) pp. 205-206.

14) S. Awazu, M. Itoh, S. Kozasa and K. Satoh: Planning of Reinforcement Concrete, (Ohm-sha, 2000) pp. 18-24.

15) Electrochemical Measurement Manual, (Japan Electrochemistry Soc., Maruzen, 2002) pp. 53-66.

16) N. Ohtsuki, S. Miyasato, K. Minagawa and S. Hirayama: Concrete Res. \& Tech., 10 (1999) 43-49.

17) Chemistry Handbook, (Japan Chem. Soc., Maruzen, 1998) pp. 11801185 . 